American Research Journal of Humanities and Social Sciences

(ARJHSS)

ISSN (Online) : 2378-7031

AMERICAN RESEARCH JOURNALS

An Academic Publishing Frouse

Volume 2, 2016, 1- 11 pages

DOI: 10.21694/2378-7031.16016

Research Article

Open Access

\title{
Benefits and Barriers: Incorporating Assistive Technology in an Inclusive Setting for Primary School Students with Learning Disabilities in Language Arts
}

\author{
Sami Alharbi \\ Sami-tu@hotmail.com
}

Abstract: This papers illustrates the specific need of assistive technology for teach students with learning disabilities when they inclusive them in public schools. This papers focus on use assistive technology in the classroom, but there are some barriers to use assistive technology and overcoming the barriers to implementing assistive technology for students with specific learning disabilities in the general classroom to teach them language arts so that its benefits can be realized. Also, to investigate the effectiveness of several intervention: training special and general education teachers and providing support in the schools through technical professionals and parents involvement.

\section{INTRODUCTION}

As societies' understanding of disabilities has grown, and with it, the educational opportunities available for students with specific learning disabilities in various academic areas such as math, reading, and writing. Nevertheless, many instructors working at the K-12 school level are aware of the absence of sufficient proficiency in reading, science, and mathematics, among those with learning disabilities (Anderson, Anderson, \& Cherup, 2009). The Education for All Handicapped Children Act in 1975, which became the Individuals with Disabilities Education Act (IDEA) of 2004, demanded that schools instruct learners with disabilities and non-disabled peers in the same social and academic institutions (Martin, Martin, \& Terman, 1996). Smith (2005) states that this act was later reauthorized as the Individuals with Disabilities Education Improvement Act, and as part of its requirements, it was later made necessary for special education teachers to have specific qualifications. On the same note, this directive holds learning institutions accountable for ensuring that those learners with learning disabilities take part in state testing and are listed in the records of adequate annual progress (Alper \& Raharinirina, 2006). Despite legislation and provisions that have helped to make education more accessible to students with learning disabilities, difficulties still exist. Many teachers experience problems reaching goals set by their individualized learning programs for various reasons (Anderson, Anderson, \& Cherup, 2009).

As a teacher of students with learning disabilities, my experience with some students who had difficulty in reading, specifically connecting letter recognition with pronunciation revealed that using assistive technology is extremely effective when implemented easily and competently. After attempting several traditional strategies, technology was used to assist the students. The students began using computer based reading programs. After using the program, the students' pronunciation greatly increased. The problem of limited access to learning and education is what was holding these students back. It was because of this technology that the students were able to access the information being taught. According to Basham and Marino (2013) students with learning disabilities need accommodations. One primary source of such technology are computers which are utilized to assist in learning. 


\section{Statement of Problem}

The rising number of learners with disabilities in general classrooms in public schools present sophisticated challenges for instructors including demands for accountability, inclusion, as well as, changes in teaching practices (Bausch \& Ault, 2008). On the same note, incorporating technologies into their lesson is a challenge for some instructors due to apprehension while using unacquainted technology, absence of training, and because of the lack of onsite support (Alper \& Raharinirina, 2006). Admittedly, the technology may be challenging for instructors (Anderson et at., 2009). Even for students with learning disabilities, benefits of technology use in the classroom are not yet perfect. Technology has been shown to have mixed results as a tool for students with mild disabilities, However, according to the results of studies done, overall, it has proved to be a benefit for students in the majority of areas such as reading, where the implementation of technology was shown to improve the learning environment and resulted in fundamentally significant improvements (Anderson et at., 2009). In addition, in spite of any difficulties teachers may face in implementing technology, the consequences of not doing so are far graver in terms of limiting access to education to students with learning disabilities.

Essentially, teaching modifications using assistive technology as a globally designed system can promote participation, access, as well as, the progress of learners with disabilities; and can create flexible engagement, instruction, and assessment, which minimize barriers at the beginning of the learning process (Bandura, 1986). However, despite the steady rise of assistive technologies, instructors in the classroom settings have carried out limited studies on the effectiveness of using assistive technology. The problem is how to overcome the barriers to implementing assistive technology for students with specific learning disabilities in the general classroom so that its benefits can be realized.

\section{Purpose of the Project}

In the current public learning institutions, general education instructors Barfurth and Michaud (2008) achieved a large number of classroom accommodations for students with learning disabilities. Although general education instructors are specialists in certain content, the majority have little training in special education. This is in line with Basham and Marino's (2013) assertion that though special education instructors work closely with general instructors to offer knowledge and assistance, they do not work in many general education classrooms where they can supervise the use of the accommodations including assistive technology. Because of that, the implementation of assistive technology for students with learning disabilities is overlooked. Therefore the purpose of this paper is to investigate the effectiveness of several interventions such as training special and general education teachers, and providing support in schools through technical professionals and parents. The process for achieving this would involve new in-service teacher training, creating a technology resource department in schools, training teachers to use technology, and providing resources and information for parents to increase involvement.

\section{DEFINITION OF TERMS}

\section{Accommodation}

The change in standard, course, location, test preparation, timing, expectations, scheduling, expectations learner response, as well as, another attribute. This change give access for a learner with a disability to take part in a standard, course or test but primarily does not change or lower the standard, course or test (Bausch, \& Ault, 2008).

\section{Adaptive/ Assistive Technology}

Refers to any equipment, item or product system either obtained, off the shelf, commercially or customized and used to maintain, increase or improve functional capacity for a person with disabilities (Alper, \& Raharinirina, 2006). 


\section{Adaptive Technology Service}

Refers to any service, which directly helps a person having a disability in acquisition, selection, or utilization of an adaptive technology device (Anderson et al., 2009).

\section{High Technology Device}

A high technology device refers to a complex expensive mechanical or electronic piece of machine (Bandura, 1986).

\section{Learning Disability}

Refers to a disorder, which influences the capability of the person to use or understand written or spoken language. It can be determined by challenges with thinking, listening, reading, speaking, spelling, and speaking, as well as, mathematical calculations (Bauer \& Kenton, 2005).

\section{Low Technology Device}

Refers to assistive technology equipment that is non-electric and low cost.

\section{UDL (Universal Design for Learning)}

Refers to instructional materials and curriculum, which follow guidelines to offer access to the academic content that the classroom environment for learners with several abilities from different backgrounds.

\section{LITERATURE REVIEW}

As mentioned, overcoming the barriers to implementing assistive technology for students with specific learning disabilities in the general classroom will allow access to the benefits of that technology. Presently, there are many students with learning disabilities in schools across America, and the achievement gap remains an important issue for these students, since there is pressure on them to satisfy the demands of the general education curriculum (Parette \& McMahan, 2002). Stress of performing is particularly real for those learners transitioning into secondary levels where curricular objectives are enhanced to satisfy the expectations of high stakes testing. Fortunately, developments in technology, including assistive technology are present to enhance the academic achievements of students with learning disabilities. Despite their availability, many instructors feel intimidated and unsuccessful in this endeavor because of barriers they face in implementing technology they lack knowledge about. Against this backdrop, this literature review will examine benefits and importance of assistive technology, existing barriers to implementing assistive technology in inclusive setting for learners with learning disabilities and the ways to overcome those barriers.

\section{Defining Assistive Technology for Youth with Learning Disabilities}

There are several definitions for assistive technology, and each one suggests a different emphasis depending on who is being assisted. The formal definition of assistive technology comes from the Assistive Technology Act of 1998 which was amended in 2004, and states that it is "Any item, piece of equipment or product system whether acquired commercially off the shelf, modified, or customized that is used to increase, maintain or improve functional capabilities of individuals with disabilities" (Cook \& Polgar, 2014, p. 2). This definition focuses on improving capabilities. Another definition according to Pearman (2008) states that assistive technology refers to technology specially designed or adapted to enhance the functioning of individuals with disabilities. This definition points to high level technology. Today in the U.S., assistive technology is commonly thought of as high level technology, essentially hardware including alternative keyboards, screen magnifiers, as well as, software such as onscreen keyboards, optical character recognition, as well as, voice recognition (Pelgrum, 2001). Even 
more specifically, in academic settings, assistive technology according to Schoepp (2005) is any technological devices or tools, which assist learners with disabilities to access learning materials and carry out learning tasks effortlessly. However, for the aim of this research, assistive technology will refer exclusively to discrete trial training (DTT)s, which are designed particularly for learners with learning disabilities to access the instructional materials more effectively.

Assistive technology encompasses the use of computer software or hardware, but it also includes a variety of other forms of adaptations and accommodations that allow people with learning disabilities to work more independently. It is instrumental that instructors recognize that there are various forms of educational computer use; however, not all computer use within the classroom is viewed as the computer assisted teaching. Computers, according to Basham and Marino (2013) are vital forms of assistive technology since they offer several possibilities for writing, reading, finding information, speaking, or controlling a person's environment. On their assertion, Bauer and Kenton (2005) claimed that computers are very popular fixtures within classrooms, making technology an efficient approach for several educational tasks. This is especially pertinent these days as the information age is constantly introducing different types of technology. The constant growth of technology that is available to assist students with learning disabilities is one sign of its effectiveness.

\section{Effectiveness of Assistive Technology}

Despite improving access to technology, the extent and frequency to which special and general education instructor use assistive technology in their inclusive classrooms are unknown. Hence this portion of this research will examine the effectiveness of the use of assistive technology by general education instructors within the inclusive classrooms. The study of the effectiveness of using assistive technology within the inclusive setting is instrumental for several reasons. First, study within this field will improve present literature in the field and the way the general and special education instructors view the purpose of enacting assistive technology for their learners with learning disabilities. On the same note, increasing teacher knowledge and skills of assistive technology can benefit students and teachers with specific learning disabilities.

When students with learning disabilities are not able to achieve academic goals, it is instrumental for educators and families to recognize the role of the disability in the prevention of education performance and plan suitable interventions. These interventions normally emanate from a learner's individualized program that describes the education demands in the form of objectives and goals for learners and offers a blueprint for services (Scott et al., 1998). Among the services that are recommended, is the adoption of assistive technology.

Principally, when the individualized education program team includes assistive technology in the short-term objectives and goals, the goals need to be specific as to why and how the assistive technology device can assist the learner to achieve the educational goals (Alper \& Raharinirina, 2006). Assistive technology enhances the chances for students who have a wide range of physical and intellectual disabilities to be more autonomous and interact in educational or social environments. On the same note, assistive technology equipment, through assisting learners learn specific social and educational tasks can assist learners remain eligible to learn in the least preventive setting. Therefore, with these objectives and goals in mind, it is paramount ton analyze the effectiveness of assistive technology in the inclusive environment for learners with disabilities.

An interview was conducted with Mr. Muhammed, a special education teacher in Saudi Arabia by Skype. Questions surrounding the effectiveness of assistive technology were discussed. Mr. Muhammed mentioned that the assistive technology helps students with learning disabilities to perfect their skills in areas that they suffer in due to their disability, such as in reading or writing. Assistive technology also allows students to shorten the time it takes to improve in trouble areas. It allows them to gain full accessibility to learning materials and 
gain control of their education. When asked about barrier for teachers, Mr. Muhammed said that teachers need more training in using assistive technology because of their lack of experience. He also talked about parent involvement, and the lack of involvement from parents as well as the lack of communication between teachers and parents. There is a great need to involve parents and perhaps, train them in the area of assistive technology as well. This serves to help create support for students with learning disabilities outside the classroom.

Indeed, several studies on the effectiveness of using assistive technology within an inclusive setting have verified that assistive technology has effects on the teacher's ability to implement technology within the classroom. Within this context, Bauer and Kenton (2005) concluded that for instructors to use technology effectively, they have to believe that technology can assist them in attaining higher degree goals more successfully and that technology will not distract higher degree goals and they will have sufficient ability and adequate resource to utilize technology. For this reason, the perception of instructors acts as a filter by which they determine the degree and priorities to which assistive technology will be incorporated into the system (Bausch, \& Ault, 2008).

\section{Effectiveness in Reading}

Literacy, including reading and writing, are areas that practical assistive technology can greatly help students with learning disabilities. As a reading intervention, it implies that the technology assist learners to improve and strengthen their general reading skills. Thus, assistive technology plays an effective role in supporting learners with learning disabilities in both of these fields. Computer programs have been established to support the achievement of basic reading skills. For instance, Barfurth and Michaud (2008) reported that the software program Write and Read Gold provides a text-reading program, which enables learners to read independently within the classroom. As such, with increased technology access, learners with disabilities can be accorded every chance to participate actively in class discussions during reading, and enjoy books, which are being read by their fellow peers.

\section{Effectiveness in Written Language}

Writing is also essential to most learning activities. Nevertheless, writing is always challenging for learners with learning disabilities. Learners with learning disabilities are more likely to face challenges in the area of spelling, punctuation, margin creation, and spacing. On the same point, Parette and McMahan (2002) attested that word processing provides clear and consistent text on the screen, and offer spelling review, as well as, a limited grammar review. In their study, Passey et al. (2004) compared learner products, some with and some without word processing, and their results revealed that learners using word processing generated writings, which reflected limited spelling errors, in addition to, better organization. In fact, all these studies revealed that the utilization of word processors could result in improved writing results for learners with learning disabilities. There are other areas as well that would benefit from assistive technologies.

\section{BARRIERS To EFfective Use of Assistive Techinology}

IDEA (2004) demands the school districts to examine learners assistive technology needs, buy the technology, and teach the staff and learners to use the assistive technology. Notwithstanding the legal obligation to offer assistive technology, a number of barriers have restricted the use of assistive technology. Bandura (1986) reviewed present literature on the utilization of assistive technology and identified several obstacles to using assistive technology with students with learning disabilities. These obstacles include the instructors' views, availability, teacher training, eligibility, as well as, student abandonment of technology. Today barriers exist as well. As argued by Mason, (2014) there are barriers to AT use on the implementation and accessibility side, including issues specifically that teachers face such as "troubleshooting support for malfunctioning technology, adequate planning and collaboration time for teachers, systems to check out technology for students, adequate 
wireless support for mobile technology, and an integrated approach across curriculum" (p. 28). These and other issues need to be addressed if progress is to be made.

For teachers, many times the primary goal is for the benefit of the student, so even in spite of Individual Education Plan (IEP), which outlines the individual resources required for that child to accommodate their needs, mandates for the use of assistive technology. When teachers observe that barriers associated with implementing assistive technology interfere with students' education, they will most likely abandon assistive technology. This is an underlying factor of the importance of dealing with such barriers.

\section{Teacher Views}

Conventionally, there have existed two views of role of assistive technology in life of an individual with disabilities. The first role is the assistive technology as cognitive prosthesis. Essentially, as a cognitive prosthesis, the assistive technology substitutes, and the capability, this is limited or absent for an individual with a disability. The other perception is that assistive technology would be a cognitive partner. Therefore, as a cognitive partner, the assistive technology supports an individual's efforts to perform or accomplish a duty. As such, instructors who perceive assistive technology as a cognitive prosthesis presume that the assistive technology does not do the task for the learner, whereas, instructors with the cognitive partner think that the assistive technology assists the learning of a student.

\section{Lack of Training}

Teacher training is another prime barrier to the effective use and implementation of assistive technology in the classroom. A study by Bausch and Ault (2008) on the classroom teacher knowledge of assistive technology reported that $41 \%$ of the even higher education teachers lacked training and knowledge in using assistive technology in their classrooms. This shows that those teachers more likely to use Assistive Technology are unprepared. Further, these instructors were not conversant with using devices and were not aware of the other assistive technology within the educational community. As for K-12 level teachers, Parette and McMahan (2002) in their study discovered that instructors who had 40 hours or more learning in assistive technology, $70 \%$ contended that assistive technology was a vital part of their daily routine. While $74 \%$ of the instructors with no training disagreed that, assistive technology was an integral component of their classroom routine. For this reason, lack of instructor training is a vital barrier in itself; nevertheless, it is also a prime cause of technology abandonment. For this reason, for a teacher to continue using the technology, the teacher must be in a position to identify the importance of the technology.

\section{Lack of Resources}

Scarcity of resources is also an obstacle to the use of assistive technology. Barfurth and Michaud (2008) carried out a study on six hundred K-12 special education instructors and their perceptions of the obstacles of using assistive technology. $70 \%$ of the respondents reported outdated equipment and computers as an obstacle to utilizing assistive technology. Because of this, they are usually reluctant to use assistive technology with a learner (Bauer \& Kenton, 2005).

Technical support is another important resource that is not being used effectively or implemented enough as an assistive technology. Generally, in the absence of effective technical support, instructors cannot be expected to solve the technology-connected issues. To be specific, in a study done by Rapp (2005), instructors reported that the prime barrier to assistive technology use within the classrooms was the absence of technical assistance. On the same note, in a study done by Rohaan et al. (2009), technical problems including computer malfunctioning, 
internet connections, slow internet connections, as well as, instructors having to work with outdated computers were found to be a prime barriers for instructors. The investigators in this research summarized that technical obstacles hindered the delivery of instruction and the natural flow of class activity, and these sequentially discouraged instructors from incorporating technology into their learning activities (Scheeler et al., 2010).

\section{Lack of Family Involvement}

The last barrier to effective use and implementation of assistive technology, according to Schoepp (2005), is the lack of collaboration with family. More often than not, assistive services and devices are most likely to be effectively identified and adopted in social and academic environments when individualized educational program teams handled family objectives connected to assistive technology. However, since the family decision concerning assistive technology can be affected by linguistic, cultural values, and background, Schulte et al. (1998) stressed that individualized educational program team members are very sensitive to every expectations of the family to maximize effective assistive technology implementation in the school, community, and home. Nevertheless, this kind of partnership is seldom established because of barriers that families face concerning assistive technology use and selection.

All in all, assistive technology within educational settings can be instrumental to the achievement of learning for learners with learning disabilities. In fact, it is viewed to be compensatory since the devices can be utilized to improve the ability of an individual who has a learning disability to independently do or carry out a task at the anticipated level (Alper, \& Raharinirina, 2006). As a result, incorporating suitable assistive technology in general learning classroom can assist in keeping students with learning disabilities engaged in learning. To solve this problem, it is necessary therefore to explore ways to make its implementation a beneficial process by addressing the barriers teacher face. Once barriers are understood, it is possible to begin constructing a plan to overcome them.

\section{SOLUTION/FRAMEWORK}

\section{Recommended Assistive Technology Incorporation Model}

To better prepare competent instructors who can work with various populations, in-service education initiatives should include assistive technology teaching. Teaching assistive technology is a part of the solution to the problem of overcoming barriers to assistive technology implementation for students with specific learning disabilities in the general classroom. Due to the legislation regarding individualized education plans, as well as, the increasing awareness of the population of individuals with disabilities, present and future instructors require more experience with issues connected to individuals with learning disabilities such as assistive technology. The purpose of this would satisfy not only the legal requirements, but also the need for more training in assistive technology. Currently, the need for more training exists due to the barriers, which interrupt to teaching process. Principally, assistive technology approaches can offer access to information and curriculum in several formats to satisfy the learning demands of students with a variety learning disabilities. Assistive technology equipment can be employed to maintain, increase, or enhance functional capabilities of students with learning disabilities.

As a result, to fill this gap in knowledge, there is a need to increase the number of courses that expose primary level teachers to assistive technology as it relates to instructing students with specific learning disabilities. This is important and necessary so that all students are able to gain equal access to education, whether they have a specific learning disability or not. In fact, general inclusion strategies and concepts need to be taught throughout the key content and required method classes (Alper, \& Raharinirina, 2006). In essence, these courses need to include teacher planning, educational methods, literacy, and reading, as well as, instructional technology. 


\section{Plan to Address Problem}

To address the issue of overcoming the barriers to implementing assistive technology in the class room, the specific problems mentioned in the literature review will all be address with in introduction of a Technology Resource Center (TRC) in the school. This TRC will be a new department within the school, which will provide technology resources and will also provide training in the specific area of assistive technology. In order to do this, technical professionals will be hired to do training for assistive technology for not only special education teachers, but general education teachers as well, and even parents of children with disabilities. The plan will also include access to technical professionals and in-service training for teachers; and parent assistance and access to technology resources.

\section{Teacher Training}

Lack of instructor training has been mentioned as a prime barrier for effective usage and implementation of assistive technology. Therefore, to handle this concern, grant money will need to be allocated for setting up a resource center, hiring technical professionals, and training instructors on how to employ assistive technology within their instruction and methods for teaching learners with learning disabilities on how to utilize the technology. The TRC would be a space within the school where teacher could find information, software, and hardware, such as computers and other assistive technologies for training purposes. Teachers will be required to attend in-service training once at the beginning of the semester to learn about new technology, review, and discuss skills and experiences as a way of assessing and improving the training at its initial stages. Throughout, the year, teachers will have access to trained professionals in the area of computer and assistive technologies through the office of the TRC.

As a result, to achieve this objective, instructors will utilize hardware and software within their classrooms, as well as, professional developments. Essentially, professional development lessons will train instructors to utilize this technology, and also make the instructors aware of challenges, benefits, as well as, how to successfully employ assistive technologies. This will also require the approval of administrative personnel in the school and from the management in educational institutions because of the necessity of school funding to support the project.

\section{Parent Involvement}

Undeniably, parent involvement is instrumental to the success of the plan since learners should be encouraged by both the parents and teachers to use the assistive technology. During the initial assessment stage for their child, while discussing the IEP, the parent can be introduced to the idea of assistive technology. At that time, a recommendation can be made to utilize assistive technology in the home. For this aspect of the plan, parents of children with disabilities will be asked to attend a one day class to explain the opportunities and resources that are provided by the new TRC. After which, they will have year-round access to the technology resources and technical professionals. Parents will be able to contact the TRC by e-mail anytime or in person for an hour after school.

Parent involvement according to Anderson et al. (2009) increases the learners' motivation to utilize assistive technology and maximizes the advantages of the assistive technology. On the same note, parent involvement will inform the parents about the success and benefits of assistive technology, improve parent interest in motivating learners to use assistive technology. By letting parents have access to technology resources, they will be better prepared to assist children and create positive results using their new knowledge of assistive technology. 


\section{EvaluATiON}

To evaluate the effectiveness of the plan, the goals that were to be achieved will need to be clearly known and assessed. These goals include, primarily eliminating the barriers to utilizing assistive technology for students with disabilities. This includes increasing teacher experience with and access to assistive technology through in-service training. It also includes involving parents through providing access to assistive technology resources, all of which will be achieve with the introduction of a TRC and technical professionals.

\section{Evaluation Process}

The evaluation method will use a questionnaire to assess changes in teacher views. The rationale for using a questionnaire for to collect the data is that it is the easiest way to get the information about access from teachers and parents. In addition, a questionnaire can provide many types of data, both qualitative and quantitative. The questionnaire will be given at the beginning and end of the year, and will inquire about the general and special education teachers' view about whether teachers views, based on the training and in-service activities believe that assistive technology to be a cognitive prosthesis and presume that the assistive technology does not do the task for the learner, or whether they think it is a cognitive partner, where assistive technology assists the learning of a student. A successful evaluation would show the majority, if not all teachers viewing assistive technology as a cognitive partner.

\section{Teacher Assessment}

The next evaluation will be on the teacher training. Irrefutably, no assistive technology enactment plan would be complete without demarcating the plans for the teacher training. As a result, immediately after the assistive technology has been established, the evaluation will be done based on examining the training required, the specific software or hardware, as well as, who to provide the training. Therefore, before the training periods, participating members of the team should revisit the learners individual education plan goals, as well as, review the learners' daily activities to make sure that the training activities are concentrated on learning those aspects of the technology that will be implemented with learners. Teacher evaluation and examination will take place once at the beginning and once at the end of the school year. Throughout the school year, data will be collected by the office of TRC. This will serve the purpose of not interruption learning as much as possible. As attested by Ault et al. (2013), depending on the assistive technology, training may be disruptive to other learner within a classroom setting and the learner may be disruptive to other learners within a classroom environment thereby distracting other learners from classroom activities.

The teacher training can also be evaluated through examining the activities, which are used to educate the students. Accordingly, Balanskat et al. (2006) attested that since learning technology itself puts a cognitive burden on the learner, teams should, as a result, consider utilizing lower cognitive duties when finishing training activities. For instance, if the learner needs to learn how to utilize word processing characteristics, the team needs to offer the student with some manuscript to copy so that imaginative composition is not required. On the same note, to evaluate the teacher training, it is instrumental for the TRC to keep data and records on how well and how often the teacher was using the assistive technology. As such, simple checklists of knowledge mastered, anecdotal observations, as well as, scheduled evaluations can be utilized to keep a track of technology use during education training activities. 


\section{Parent Assessment}

Parents also have a substantial role in the implementation of the required assistive technologies, and ongoing involvement and influence over its effectiveness outside of the academic environment. Therefore, when family objectives are connected to assistive technologies, the parents' involvement will be measured by recording the number of parents who attend the TRC. The evaluation will examine the equipment that is available to support the parents of children with learning disabilities. Because of barriers families face concerning assistive technology use and selection, it is important to know how available resources were to parents at any given time. Parents will also be given a questionnaire to determine their satisfaction with the TRC and all the resources available.

\section{REFERENCES}

Alper, S., \& Raharinirina, S. (2006). Assistive technology for individuals with disabilities: A review and synthesis of the literature. Journal of Special Education Technology, 21(2), 47-64.

Anderson, C. L., Anderson, K. M., \& Cherup, S. (2009). Investment vs. return: Outcomes of special education technology research in literacy for students with mild disabilities. Contemporary Issues in Technology and Teacher Education, 9(3), 337-355.

Ault, M. J., Bausch, M. E., \& McLaren, E. M. (2013). Assistive technology service delivery in rural school districts. Rural Special Education Quarterly, 32(2), 15-22.

Balanskat, A., Blamire, R., \& Kefla, S. (2006). A review of studies of ICT impact on schools in Europe, 12(12), 20-28.

Bandura, A. (1986). Social foundations of thought and action: A social cognitive theory. Englewood, NJ: Prentice-Hall.

Barfurth, M. A., \& Michaud, P. (2008). Digital video technologies and classroom practices. International Journal of Instructional Media, 35(3), 301-315.

Basham, J. D., \& Marino, M. T. (2013). Understanding STEM education and supporting students through universal design for learning. Teaching Exceptional Children, 45(4), 8-15.

Bauer, J., \& Kenton, J. (2005). Toward technology integration in the schools: Why it is not happening. Journal of Technology and Teacher Education, 13(4), 519-546.

Bausch, M., \& Ault, M. (2008). Assistive Technology Implementation Plan. Teaching Exceptional Children, 41(1), 6-14.

Cook, A. M., \& Polgar, J. M. (2014). Assistive technologies: Principles and practice. Elsevier Health Sciences.

Martin, E. W., Martin, R., \& Terman, D. L. (1996). The legislative and litigation history of special education. The Future of Children, 25-39.

Mason, T. (2014). Transforming teaching: Implementing mobile technology learning strategies in serving students with visual impairments (Doctoral dissertation, Texas Tech University).

Parette, P., \& McMahan, G. A. (2002). What should we expect of assistive technology? Teaching Exceptional Children, 35(1), 56.

Passey, D., Rogers, C., Machell, J., McHugh, G. \& Allaway, D. (2004). Emergent findings: The motivational effect of ICT on pupils. London: DfES. 
Pearman, C. (2008). Independent reading of CD-ROM storybooks: Measuring comprehension with oral retellings. Reading Teacher, 61(8), 594-602.

Pelgrum, W. J. (2001). Obstacles to the integration of ICT in education: Results from a worldwide educational assessment. Computers \& Education, 37, 163-178.

Rapp, W. H. (2005). Using assistive technology with students with exceptional learning needs: When does an aid become a crutch? Reading \& Writing Quarterly, 21(2), 193-196.

Rohaan, E. J., Taconis, R., \& Jochems, W. G. (2009). Measuring teachers' pedagogical content knowledge in primary technology education. Research in Science \& Technological Education, 27(3), 327-338.

Scheeler, M., Congdon, M., \& Stansbery, S. (2010). Providing immediate feedback to co-teachers through bug-in-ear technology: An effective method of peer coaching in inclusion classrooms. Teacher Education and Special Education, 33(1), 83-96.

Schoepp, K. (2005). Barriers to technology integration in a technology-rich environment. Learning and teaching in Higher Education: Gulf Perspectives, 2(1), 1-24.

Schulte, A. C., Osborne, S. S., \& Erchul, W. P. (1998). Effective special education: A United States dilemma. School Psychology Review, 27, 66-76.

Scott, B. J., Vitale, M. R., \& Masten, W. G. (1998). Implementing instructional adaptations for students with disabilities in inclusive classrooms. Remedial \& Special Education, 19(2), 106.

Smith, T. E. (2005). Idea 2004 Another Round in the Reauthorization Process.Remedial and Special Education, 26(6), 314-319.

Citation: Sami Alharbi, "Benefits and Barriers: Incorporating Assistive Technology in an Inclusive Setting for Primary School Students with Learning Disabilities in Language Arts". American Research Journal of Humanities and Social Sciences, Volume 2, pp:1-11

Copyright (c) 2016 Sami Alharbi, This is an open access article distributed under the Creative Commons Attribution License, which permits unrestricted use, distribution, and reproduction in any medium, provided the original work is properly cited. 